\title{
Short communication: Stabilization of milk proteins at pH 5.5 using pectic polysaccharides derived from potato tubers
}

\author{
Robert B. Peterson, Scott A. Rankin, and Shinya Ikeda*† \\ Department of Food Science, University of Wisconsin, Madison 53706
}

\section{ABSTRACT}

Potato pectin has unique molecular characteristics that differentiate it from commercially available pectins sourced from citrus peels or apple pomace, including a higher degree of branching and a higher acetyl content. The objective of this study was to evaluate the ability of potato pectin to stabilize milk proteins at an acidic $\mathrm{pH}$ above their isoelectric point, $\mathrm{pH} 5.5$, at which no citrus- or apple-derived pectins are functional. Potato pectin was extracted from raw potato tubers by heating at $\mathrm{pH} 4.5$ and $120^{\circ} \mathrm{C}$ for 30 min after removing starch solubilized using a dilute $\mathrm{HCl}$ solution adjusted to $\mathrm{pH}$ 2. The potato pectin was found to have a galacturonic acid content of $17.31 \pm 3.29 \%$ (wt/wt) and a degree of acetylation of $20.20 \pm 0.12 \%$. A portion of the potato pectin was deacetylated by heating it in an alkaline condition. The deacetylation resulted in a galacturonic acid content of $19.12 \pm 4.64 \%$ (wt/wt) and a degree of acetylation of $3.03 \pm 0.03 \%$. Particle size distributions in acidified milk drink (AMD) samples adjusted to $\mathrm{pH}$ 5.5 demonstrated that the acetylated and deacetylated potato pectins were capable of inhibiting the aggregation of milk proteins to the largest degree at a pectin concentration of 1.0 and $0.25 \%$ (wt/wt), respectively. Pectin molecules that were not bound to milk proteins in these AMD samples were quantified after centrifugally separating milk proteins and pectin bound to them from the serum. We found that, for the acetylated and deacetylated potato pectins, all or approximately half of the pectin molecules were bound to milk proteins at a pectin concentration of 0.25 or $1.0 \%$ (wt/wt), respectively. These results suggest that the presence of acetyl groups is a critical factor that determines how potato pectin molecules bind electrostatically to milk protein surfaces, form 3-dimensional structures there, and function as a stabilizer. The present results demonstrate that potato pectin can stabilize milk proteins at

Received January 29, 2019.

Accepted May 7, 2019

*Corresponding author: shinya.ikeda@obihiro.ac.jp

†Current address: Department of Life and Food Sciences, Obihiro University of Agriculture and Veterinary Medicine, Obihiro, Hokkaido 080-8555, Japan.
$\mathrm{pH} 5.5$ and potentially enable the development of novel AMD products with improved functionality for caseincontaining products with moderately acidic $\mathrm{pH}$ profiles. Key words: acidified milk, milk protein, pectin

\section{Short Communication}

Acidified milk drinks (AMD) are functional dairy beverage products that are gaining in popularity and demand because of the physiological benefits that milk proteins provide (Syrbe et al., 1998; Corbo et al., 2014). These drinks are produced by directly adding acid or juice as an acidulant to milk or fermenting milk with lactic acid bacteria (Liu et al., 2006). As the $\mathrm{pH}$ decreases, the $\mathrm{k}-\mathrm{CN}$ hairy layer surrounding the casein micelle loses its negative charges and collapses onto the micelle surface, leading to a loss of steric repulsion between casein micelles and inducing micelle-micelle aggregation (Dalgleish, 1998; Sejersen et al., 2007). To prevent excessive aggregation of casein micelles, which may result in the separation of milk proteins from the liquid phase, polysaccharide stabilizers such as high methoxyl pectin (Laurent and Boulenguer, 2003) and carboxymethyl cellulose (Ntazinda et al., 2014) are frequently added to AMD products. These polysaccharides have negatively charged carboxyl groups that can electrostatically bind to positively charged patches on the casein micelle surface (Tuinier et al., 2002; Tromp et al., 2004; Jensen et al., 2010). Unbound parts of the polysaccharide molecule then form loops and loose ends or tails extending into the aqueous phase. These loops and tails compensate for the loss of steric repulsions between casein micelles and prevent excessive casein-casein aggregation in AMD (Tromp et al., 2004; Sejersen et al., 2007; Jensen et al., 2010). However, existing polysaccharide stabilizers function through this mechanism in a rather narrow $\mathrm{pH}$ range around $\mathrm{pH} 3.2$ to 4.2 , limiting their application to AMD in the high-acid category (Laurent and Boulenguer, 2003; Nakamura et al., 2006; Cai et al., 2017).

Potato pectin differs from the pectins typically used in AMD in various structural aspects. The latter are commonly derived from citrus peels or apple pomace and are classified as high methoxyl (HM) pectin be- 
cause more than a half of galacturonic acid (GalA) residues are methyl-esterified. Potato pectin has a much lower degree of esterification, typically 17 to $30 \%$, and is therefore classified as low methoxyl (LM) pectin (Turquois et al., 1999). Potato pectin also has a much lower proportion of homogalacturonan (HG) and a much higher proportion of rhamnogalacturonan I (RG-I; Harris, 2009). In potato pectin, HG and RG-I account for approximately 20 and $75 \%$ of the molecule, respectively (Harris, 2009), compared with an average of $65 \% \mathrm{HG}$ and 20 to $35 \%$ RG-I in pectins derived from other species of plants (Mohnen, 2008). The RG-I region of potato pectin consists of a backbone of alternating $\alpha$-D-GalA and $\alpha$-L-rhamnosyl residues (Harris, 2009) and branched side chains mainly composed of galactose, arabinose, and rhamnose (Willats et al., 2006). Additionally, potato pectin is highly acetylated, occurring in GalA residues in both HG (Turquois et al., 1999) and RG-I regions (Schols and Voragen, 1994). In the HG region, the acetyl group is located most frequently at the $\mathrm{C} 3$ position, whereas in the RG-I region, the acetyl group is predominantly found at the $\mathrm{C} 2$ position (Ishii, 1997). The degree of acetylation (DA) or the proportion of acetylated GalA residues to all GalA residues was determined to be approximately 9 to $15 \%$ for potato pectin (Turquois et al., 1999; Yang et al., 2018 ) or 1 to $5 \%$ for citrus and apple pectins (Yang et al., 2018).

The unique structural characteristics of potato pectin may confer unique functional properties as a food ingredient. Yang et al. (2018) showed that the potato pectin that they prepared in the laboratory had a greater emulsifying ability as well as a greater emulsionstabilizing ability than commercially available citrus and apple pectins. The improved functionalities of the potato pectin may be attributed at least partly to its high DA because the methyl portion of the acetyl group is considered to shift the overall hydrophilicity-hydrophobicity balance of the molecule to the hydrophobic side (Dea and Madden, 1986). However, the ability of potato pectin to stabilize milk proteins has rarely been investigated. The objective of the present study was to evaluate the ability of potato pectin to stabilize milk proteins at $\mathrm{pH} 5.5$, at which neither citrus- nor apple-derived HM pectin is functional. Potato pectin was extracted from raw potato tubers in the laboratory and a portion of the pectin sample was deacetylated. The potato pectin and deacylated potato pectin were used as a stabilizer in AMD samples adjusted to $\mathrm{pH}$ 5.5 using glucono- $\delta$-lactone (GDL) as an acidulant. Particle size distributions as well as the quantities of pectin molecules bound to milk proteins in these AMD samples were determined to evaluate the ability of potato pectin to stabilize milk proteins at this $\mathrm{pH}$.
Potato pectin was extracted from Russet Burbank potato tubers grown at the University of Wisconsin Hancock Agriculture Research Station (Hancock, WI) in 2017. Potato tubers were washed, peeled, cut into small pieces, and suspended in a dilute $\mathrm{HCl}$ solution adjusted to $\mathrm{pH} 2$. The suspension was incubated at $5^{\circ} \mathrm{C}$ for $24 \mathrm{~h}$. After centrifugation at $5,500 \times g$ for $30 \mathrm{~min}$, the supernatant containing dissolved starch was discarded. The precipitate was resuspended in 5 volumes of deionized water, adjusted to $\mathrm{pH} 4.5$ using $\mathrm{NaOH}$, and heated at $120^{\circ} \mathrm{C}$ for $30 \mathrm{~min}$. After being cooled to room temperature, the suspension was centrifuged at 5,500 $\times g$ for $30 \mathrm{~min}$. The supernatant containing pectin was dialyzed overnight against deionized water using a 3.5 kDa molar mass cutoff membrane (Thermo Scientific, Rockford, IL), and then freeze-dried. Deacetylation of the potato pectin was carried out by adding $80 \mathrm{mg}$ of $\mathrm{NaOH}$ per g of pectin to a $2 \%$ (wt/wt) pectin solution and then incubating the solution at $70^{\circ} \mathrm{C}$ for $45 \mathrm{~min}$. The content of GalA residues was determined using a colorimetric carbazole-sulfuric acid method (Taylor, 1993). To $200 \mu \mathrm{L}$ of pectin solution, concentrated sulfuric acid $(3 \mathrm{~mL})$ was added and mixed thoroughly, followed by the addition of $100 \mu \mathrm{L}$ of a $0.1 \%$ (wt/wt) carbazole solution in ethanol. After incubation at $60^{\circ} \mathrm{C}$ for $1 \mathrm{~h}$, the absorbance of the sample solution was measured on a spectrophotometer at $530 \mathrm{~nm}$. The content of acetyl groups was determined using the method of McComb and McCready (1957). To $5 \mathrm{~mL}$ of pectin solution, $2 \mathrm{~mL}$ of a 1:1 mixture of an $8.60 \%$ (wt/wt) $\mathrm{NaOH}$ solution and $3.61 \%$ (wt/wt) hydroxylamine hydrochloride solution were added. After $5 \mathrm{~min}, 5 \mathrm{~mL}$ of $4.93 \%$ (wt/wt) perchloric acid in methanol was added and the solution was brought to $25 \mathrm{~mL}$ using a ferric perchlorate buffer $\left[0.23 \%\right.$ (wt/wt) $\mathrm{FeCl}_{3} \cdot 6 \mathrm{H}_{2} \mathrm{O}, 1.58 \%$ (wt/wt) perchloric acid]. After $5 \mathrm{~min}$, the sample was filtered using filter paper (Fisherbrand P8, Fisher Scientific Co., Pittsburgh, PA). The absorbance of the filtrate was measured on a spectrophotometer at $520 \mathrm{~nm}$.

To prepare AMD samples, low-heat NDM produced in the Babcock Dairy Plant (Madison, WI) was reconstituted to a $17 \%$ solids (wt/wt) solution using deionized water. Sodium azide $(0.04 \% \mathrm{wt} / \mathrm{wt})$ was added to prevent microbial growth. The NDM solution was heated at $60^{\circ} \mathrm{C}$ for $2 \mathrm{~h}$ to fully hydrate the milk solids and then at $80^{\circ} \mathrm{C}$ for $15 \mathrm{~min}$ to simulate pasteurization. A pectin solution $(2 \% \mathrm{wt} / \mathrm{wt})$ was prepared separately and heated at $70^{\circ} \mathrm{C}$ for 30 min to ensure full hydration. The NDM solution, pectin solution, GDL, and deionized water were mixed at prespecified ratios to give a final milk solids concentration of $8.5 \%$ (wt/wt), a pectin concentration of 0 to $1.0 \%$ (wt/wt), and a GDL concentration of $0.7 \%$ (wt/wt). These samples were then incubated at room temperature for $24 \mathrm{~h}$, adjusted 
to pH 5.5 using $6 \mathrm{~N} \mathrm{HCl}$, homogenized at $40 \mathrm{MPa}$ using a high-pressure homogenizer (Emulsiflex-B3, Avestin Inc., Ottawa, ON, Canada), and stored at $4^{\circ} \mathrm{C}$ for 24 $\mathrm{h}$ before evaluation. All samples were prepared in triplicate. Particle size distributions in the AMD samples were measured using a MasterSizer 2000 (Malvern Instruments Ltd., Malvern, UK). To calculate volumebased particle size distributions, the refractive index of particles and that of the dispersant were set to 0.01 and 1.56, respectively. All measurements were performed in triplicate and the results averaged. To quantify pectin bound to milk protein, the AMD samples were centrifuged at $13,000 \times g$ for $30 \mathrm{~min}$. The supernatant containing unbound pectin was dialyzed against deionized water using a $50 \mathrm{kDa}$ molar mass cutoff dialysis tubing (Spectrum Labs, Rancho Dominguez, CA), adjusted to $\mathrm{pH} 4.6$ using $6 \mathrm{~N} \mathrm{HCl}$, and then centrifuged at 13,000 $\times g$ for $30 \mathrm{~min}$. Unbound pectin in the supernatant was quantified using the colorimetric carbazole-sulfuric acid method described above.

The yield of extraction of the potato pectin was 8.68 $\pm 2.27 \%$ (wt/wt), which was in the same range as the previously reported yields of potato pectins extracted using 5 different acids, varying from 4.08 to $14.34 \%$ (wt/wt; Yang et al., 2018). The GalA content of the present potato pectin was $17.31 \pm 3.29 \%$ (wt/ wt) and that of the deacetylated potato pectin was $19.12 \pm 4.64 \%$ (wt/wt). The difference between these values was found to be statistically insignificant. The DA of the potato pectin was determined to be 20.20 $\pm 0.12 \%$, which was higher than published values of $15.0 \%$ (Turquois et al., 1999) and 9.21 to $15.38 \%$ (Yang et al., 2018). Various factors may account for the differences in DA, including extraction conditions, potato varieties, growth conditions, and maturity levels (Harris, 2009). The deacetylation treatment of the potato pectin decreased the DA to $3.03 \pm 0.03 \%$. This value was significantly lower than the potato pectin before deacetylation $(P<0.05)$ and was comparable to DA values reported for commercial citrus $(<2 \%)$ and apple $(\sim 5 \%)$ pectins (Yang et al., 2018). The pectin also contained a small fraction $(<3 \%$, wt/wt) of proteinaceous components, which may provide the pectin with emulsifying abilities.

In a preliminary study, AMD samples adjusted to $\mathrm{pH}$ 5.5 were prepared without adding pectin or using 0.3 or $1.0 \%$ (wt/wt) citrus-derived HM pectin as a stabilizer. All of these samples were separated into serum and aggregated milk protein layers. Particle size distributions in the aggregated milk protein layers revealed the presence of major peaks around $120 \mathrm{~nm}, 6 \mu \mathrm{m}$, and $15 \mu \mathrm{m}$ in AMD samples prepared using 0, 0.3, and 1.0\% (wt/ wt) HM pectin, respectively (data not shown). These results demonstrated that milk proteins are unstable at
pH 5.5 and that HM pectin enhances the aggregation of milk proteins.

Figure 1 shows particle size distributions in AMD samples prepared using 0 to $1.0 \%$ (wt/wt) potato pectin as a stabilizer. All samples had a major peak around a diameter of $120 \mathrm{~nm}$, corresponding to that of individual casein micelles (Dalgleish, 2011), with a height around 6 to $9 \%$ (data not shown), indicating that significant portions of the casein micelles in these AMD samples were not aggregated. The AMD sample prepared without adding potato pectin showed a second major peak around $100 \mu \mathrm{m}$. This peak was broad and tailed toward larger diameters. Upon addition of $0.25 \%$ (wt/wt) potato pectin, the second major peak shifted to a larger diameter of $140 \mu \mathrm{m}$ and became much taller. These results indicate that the added potato pectin promoted the aggregation of milk proteins, presumably due to the bridging effect, where a single pectin molecule binds to multiple protein particles (Dickinson et al., 1989; van Oss et al., 1990). At $0.50 \%$ (wt/wt) potato pectin, the second major peak shifted to a slightly lower diameter and decreased in height. Additionally, a third peak emerged around a diameter of $3 \mu \mathrm{m}$. The height of this peak further increased with increasing potato pectin concentration to 0.75 or $1.0 \%$ (wt/wt). Particle size distributions determined separately for potato pectin solutions prepared without adding milk proteins also showed the presence of peaks around $3 \mu \mathrm{m}$, the heights of which increased with increasing potato pectin concentration (data not shown). Therefore, the peak around $3 \mu \mathrm{m}$ was considered to result from the presence of excess pectin molecules that were not bound to milk proteins. The second major peak, reflecting the particle size distributions of aggregated milk proteins, shifted to around $20 \mu \mathrm{m}$ with increasing potato pectin concentration to $0.75 \%$ (wt/wt), demonstrating the ability of the potato pectin to inhibit the aggregation of milk proteins. Upon further increasing the potato pectin concentration to $1.0 \%$ (wt/wt), the second major peak did not change in position but decreased in height to a volume frequency of approximately $0.5 \%$.

Effects of deacetylation of potato pectin on particle size distributions in AMD samples are shown in Figure 2. Similar to the results for AMD samples stabilized using acetylated potato pectin, all samples had a major peak around a diameter of $120 \mathrm{~nm}$ (data not shown). Upon addition of $0.25 \%$ (wt/wt) deacetylated potato pectin, only small peaks with heights less than a volume frequency of $0.5 \%$ were observed around 3 and 15 $\mu \mathrm{m}$, suggesting that the milk proteins were increasingly stabilized. At $0.50 \%$ (wt/wt) deacetylated potato pectin, a large peak located around $35 \mu \mathrm{m}$ emerged. The height of this peak was similar to that of the second major peak of the AMD stabilized using $0.50 \%$ (wt/ 


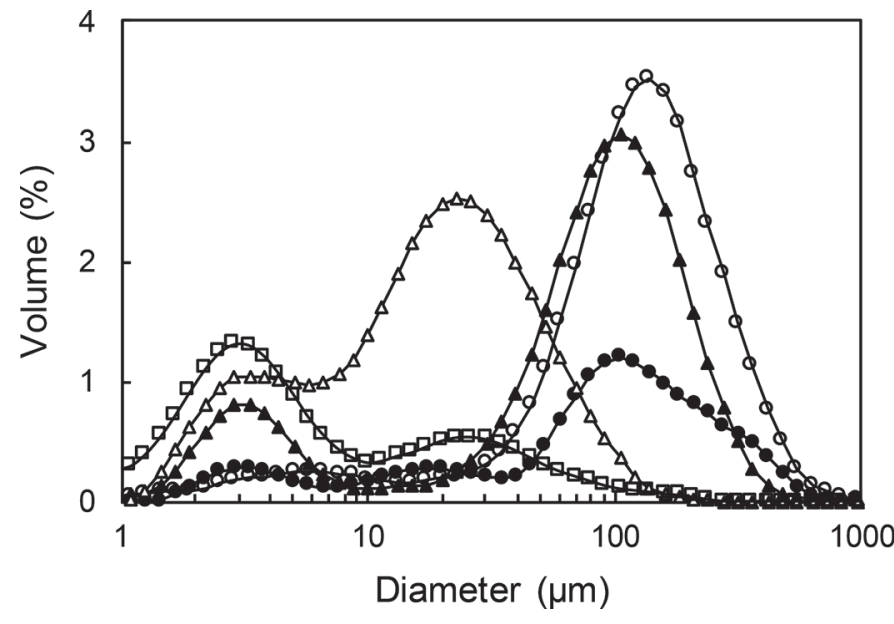

Figure 1. Volume-based particle size distributions in acidified milk drink samples adjusted to $\mathrm{pH} 5.5$ and stabilized using $0 \%$ (solid circles), $0.25 \%$ (open circles), $0.50 \%$ (solid triangles), $0.75 \%$ (open triangles), or $1.0 \%$ (squares) (wt/wt) potato pectin.

wt) potato pectin, as shown in Figure 1. However, its significantly lower diameter at the peak was considered to indicate that deacetylation of the potato pectin improved the stabilizing ability at this pectin concentration. As the concentration of the deacetylated potato pectin increased further to 0.75 and $1.0 \%$ (wt/wt), peaks emerged around 100 and $1,000 \mu \mathrm{m}$. The presence of such large particles at high levels of potato pectin suggests that the aggregation of milk proteins was enhanced, perhaps because of the depletion effect described by De Kruif and Tuinier (2001). When protein surfaces are fully covered by polysaccharide molecules, excess polysaccharide molecules that are not bound to the protein contribute to an increase in the osmotic pressure of the bulk serum phase. If protein particles come close enough to each other in such a situation, polysaccharide molecules may be depleted in the space between the adjacent protein particles, lowering the osmotic pressure of the space depleted in polysaccharide molecules. Then, the higher osmotic pressure of the surrounding solution drives water from the interparticle space into the bulk, causing further aggregation of susceptible protein particles (De Kruif and Tuinier, 2001).

In Figure 3, the quantities of potato pectin molecules that were bound to milk proteins are plotted as a function of the pectin concentration in AMD. At $0.25 \%$ (wt/ wt), no pectin was detected in the serum for both the acetylated and deacetylated potato pectins, suggesting that all of the pectin molecules were bound to casein micelles. The acetylated potato pectin promoted the aggregation of milk proteins at this concentration, as shown in Figure 1, whereas aggregation was inhibited to a greater degree as the quantity of bound pectin increased. We consider that, at 1\% (wt/wt) potato pectin, at which the best stability of milk proteins was observed, the casein micelle surfaces were most effectively covered by potato pectin molecules and the depletion effect due to unbound pectin molecules remained insignificant. It is also possible that excess pectin molecules in the serum self-assembled and formed network structures that limited the translational mobility of protein particles, thereby hindering protein-protein aggregation (De Kruif and Tuinier, 2001). In contrast, the deacetylated potato pectin showed the best stabilizing ability at $0.25 \%$ (wt/wt), at which no unbound pectin molecules were detected. Considering that the acetylated potato pectin showed the same quantity of bound pectin at the same bulk pectin concentration but promoted the aggregation of milk proteins, the deacetylation of the potato pectin most likely did not alter the quantity of pectin molecules bound to casein micelles but rather changed how the pectin molecules interacted with the micelle surfaces and formed loop and tail structures that provide steric stabilization. As the concentration of the deacetylated potato pectin increased further, so did the total quantity of bound pectin. However, the aggregation of milk proteins was enhanced, indicating that increases in the concentration of unbound pectin in the serum promoted depletion-induced protein-protein aggregation.

In conclusion, the potato pectin prepared in this study was able to inhibit the aggregation of milk proteins in AMD samples at a moderately acidic $\mathrm{pH}$ of 5.5. Conventional pectin-based stabilizers are incapable of preventing casein-casein aggregation at this $\mathrm{pH}$ because conventional HM or LM pectin binds to the casein micelle surfaces too weakly or too tightly, respectively, to form the loops and tails that provide

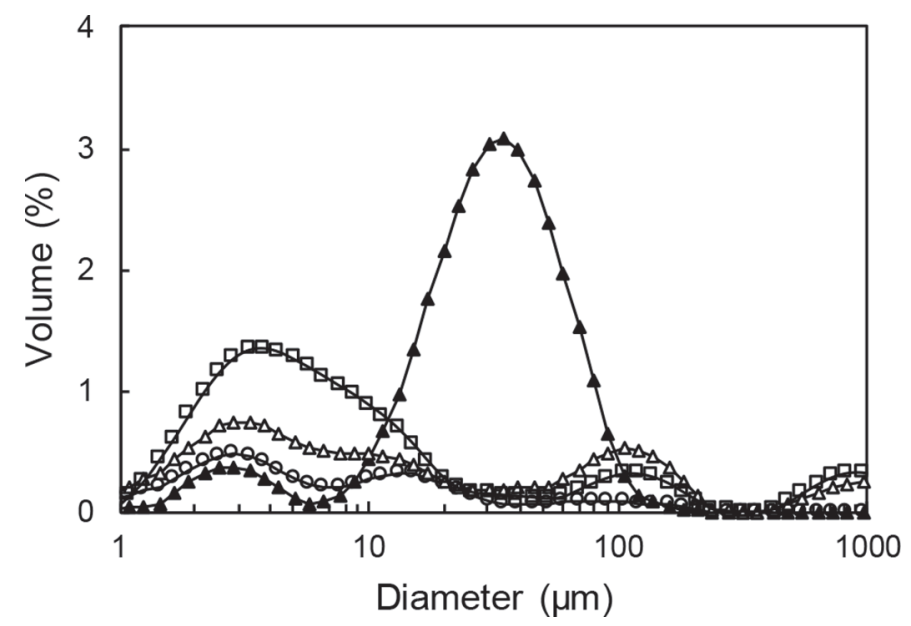

Figure 2. Volume-based particle size distributions in acidified milk drink samples adjusted to $\mathrm{pH} 5.5$ and stabilized using $0.25 \%$ (open circles), $0.50 \%$ (solid triangles), $0.75 \%$ (open triangles), and $1.0 \%$ (squares) (wt/wt) deacetylated potato pectin. 


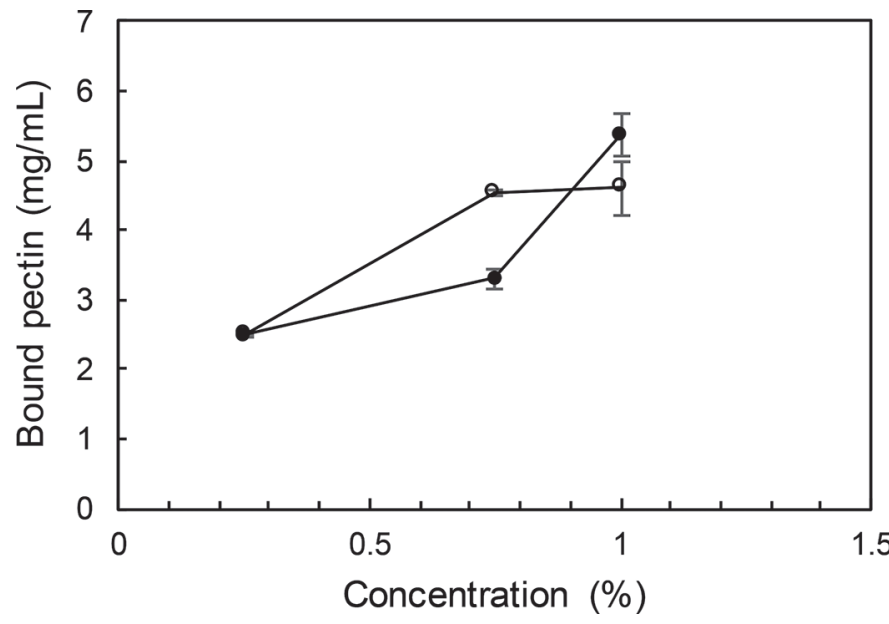

Figure 3. Quantities of potato pectin (solid circles) or deacylated potato pectin (open circles) bound to milk proteins in acidified milk drink samples adjusted to $\mathrm{pH}$ 5.5. Error bars represent SD.

steric stabilization effectively (Syrbe et al., 1998). The presence of a large proportion of RG-I in potato pectin may enable the distribution of GalA residues and negative charges along the main chain that promotes the formation of loops and tails on casein micelle surfaces at $\mathrm{pH}$ 5.5. Furthermore, side chains in the RG-I region of potato pectin that are composed of neutral sugar residues should be able to extend into the serum and provide steric stabilization effects regardless of the $\mathrm{pH}-$ dependent charged state of the whole pectin molecule. The deacetylation of potato pectin was found to have a positive effect on its ability to stabilize milk proteins at $\mathrm{pH}$ 5.5. The substitution of an acetyl group for a hydrogen atom of a GalA residue may result in stereochemical interference with the electrostatic binding of the GalA residue to a positive charge of milk protein, possibly leading to the formation of longer but fewer loops on the casein micelle surface.

\section{ACKNOWLEDGMENTS}

We thank Jiwan P. Palta of the Department of Horticulture, the University of Wisconsin-Madison, for kindly providing raw potato tubers. This work was supported by the USDA National Institute of Food and Agriculture (Washington, DC; Hatch project no. 1012819).

\section{REFERENCES}

Cai, Y., B. Cai, and S. Ikeda. 2017. Stabilization of milk proteins in acidic conditions by pectic polysaccharides extracted from soy flour. J. Dairy Sci. 100:7793-7801.

Corbo, M. R., A. Bevilacqua, L. Petruzzi, F. P. Casanova, and M. Sinigaglia. 2014. Functional beverages: The emerging side of func- tional foods commercial trends, research, and health implications. Compr. Rev. Food Sci. Food Saf. 13:1192-1206.

Dalgleish, D. G. 1998. Casein micelles as colloids: Surface structures and stabilities. J. Dairy Sci. 81:3013-3018.

Dalgleish, D. G. 2011. On the structural models of bovine casein micelles-Review and possible improvements. Soft Matter 7:22652272.

De Kruif, C. G., and R. Tuinier. 2001. Polysaccharide protein interactions. Food Hydrocoll. 15:555-563.

Dea, I. C. M., and J. K. Madden. 1986. Acetylated pectic polysaccharides of sugar beet. Food Hydrocoll. 1:71-88.

Dickinson, E., D. J. Elverson, and B. S. Murray. 1989. On the filmforming and emulsion-stabilizing properties of gum arabic: Dilution and flocculation aspects. Food Hydrocoll. 3:101-104.

Harris, P. J. 2009. Cell-wall polysaccharides of potatoes. Pages 63-81 in Advances in Potato Chemistry and Technology. J. Singh and L. Kaur, ed. Academic Press, San Diego, CA.

Ishii, T. 1997. O-acetylated oligosaccharides from pectins of potato tuber cell walls. Plant Physiol. 113:1265-1272.

Jensen, S. C. Rolin, and R. Ipsen. 2010. Stabilisation of acidified skimmed milk with HM pectin. Food Hydrocoll. 24:291-299.

Laurent, M. A., and P. Boulenguer. 2003. Stabilization mechanism of acid dairy drinks (ADD) induced by pectin. Food Hydrocoll. $17: 445-454$.

Liu, J. R., A. Nakamura, and M. Corredig. 2006. Addition of pectin and soy soluble polysaccharide affects the particle size distribution of casein suspensions prepared from acidified skim milk. J. Agric. Food Chem. 54:6241-6246.

McComb, E. A., and R. M. McCready. 1957. Determination of acetyl in pectin and in acetylated carbohydrate polymers-Hydroxamic acid reaction. Anal. Chem. 29:819-821.

Mohnen, D. 2008. Pectin structure and biosynthesis. Curr. Opin. Plant Biol. 11:266-277.

Nakamura, A., R. Yoshida, H. Maeda, and M. Corredig. 2006. The stabilizing behaviour of soybean soluble polysaccharide and pectin in acidified milk beverages. Int. Dairy J. 16:361-369.

Ntazinda, A., M. J. Cheserek, L.-X. Sheng, J. Meng, and R.-R. Lu. 2014. Combination effect of sodium carboxymethyl cellulose and soybean soluble polysaccharides on stability of acidified skimmed milk drinks. Dairy Sci. Technol. 94:283-295.

Schols, H. A., and A. G. J. Voragen. 1994. Hairy (ramified) regions of pectins. 4. Occurrence of pectic hairy regions in various plant-cell wall materials and their degradability by rhamnogalacturonase. Carbohydr. Res. 256:83-95.

Sejersen, M. T., T. Salomonsen, R. Ipsen, R. Clark, C. Rolin, and S. B. Engelsen. 2007. Zeta potential of pectin-stabilized casein aggregates in acidified milk drinks. Int. Dairy J. 17:302-307.

Syrbe, A., W. J. Bauer, and N. Klostermeyer. 1998. Polymer science concepts in dairy systems-An overview of milk protein and food hydrocolloid interaction. Int. Dairy J. 8:179-193.

Taylor, K. A. C. C. 1993. Protocols in biotechnology-A colorimetric method for the quantitation of galacturonic acid. Appl. Biochem. Biotechnol. 43:51-54

Tromp, R. H., C. G. de Kruif, M. van Eijk, and C. Rolin. 2004. On the mechanism of stabilisation of acidified milk drinks by pectin. Food Hydrocoll. 18:565-572.

Tuinier, R., C. Rolin, and C. G. de Kruif. 2002. Electrosorption of pectin onto casein micelles. Biomacromolecules 3:632-638.

Turquois, T., M. Rinaudo, F. R. Taravel, and A. Heyraud. 1999. Extraction of highly gelling pectic substances from sugar beet pulp and potato pulp: Influence of extrinsic parameters on their gelling properties. Food Hydrocoll. 13:255-262.

van Oss, C. J., K. Arnold, and W. T. Coakley. 1990. Depletion flocculation and depletion stabilization of erythrocytes. Cell Biophys. $17: 1-10$.

Willats, W. G. T., P. Knox, and J. D. Mikkelsen. 2006. Pectin: New insights into an old polymer are starting to gel. Trends Food Sci. Technol. 17:97-104

Yang, J.-S., T.-H. Mu, and M.-M. Ma. 2018. Extraction, structure, and emulsifying properties of pectin from potato pulp. Food Chem. 244:197-205. 